30. Rokos, J., Hahn. P., Koldovsky, O.. and Procházka, P.: The postnatal development of lipolytic activity in the pancreas and small intestine of the rat. Physiol. Bohemoslov, 12: 213 (1963).

31. Singh, A., Balint, J. H., Edmonds, R. H., and Rodgers, J. B.: Adaptive changes of the rat small intestine in response to a high fat diet. Biochim. Biophys. Acta, 260: 708 (1972).

32. Tomarelli, R. M., Meyer, B. J., Weaber, J. R., and Bernhard. F. W.: Effect of positional distribution on the absorption of the fatty acids of human milk and infant formulas. J. Nutr. 95. 583 (1968).

33. Walker, W. A., and Isselbacher, K. J.: Uptake and transport of macromolecules by the intestine: Possible role in clinical disorder. Gastroenterology. 67: 531 (1974).

34. Watkins, J. B., Bliss, C. M.. Donaldson, R. M., and Lester, R.: Characterization of newborn fecal lipid. Pediatrics, 53: 511 (1974).

35. Watkins, J. B., Szcepanik, P., Gould, J., Klein, P. D., and Lester, R.: Bile salt kinetics in premature infants: An explanation for inefficient lipid absorption. Gastroenterology, 64: 817 (1973).

36. Watkins, M. B., Ingall, D., Szczepanik, P., Klein, P. D., and Lester, R.: Bile salt metabolism in the newborn. New Eng. J. Med., 288: 43 ! (1973).

37. Widdowson. E. M.: Absorption and excretion of fat, nitrogen and minerals from "filled" milks by babies one week old. Lancet, ii: 1099 (1965).

38. Zoppi, G., Andreotti, G., Pajno-Ferrara, F., Njai, D. M., and Gaburro, D Exocrine pancreas function in premature and full term neontates. Pediat. Res. 6: 880 (1972).

39. Zoula J Melichar V Novík M Hahn, $P$ and Koldovský $O$ : Nitrogen and fat retention in premature infants fed breast milk "humanized" cow's milk of half skimmed cow's milk. Acta. Pediat. Scand., 55: 26 (1966).

40. New England Nuclear, Inc., Boston, Mass.

41. Calibiochem, Los Angeles, Calif.

42. Brinkman Instruments, Inc, Westbury, N. Y

43. Presented in part at the Society for Pediatric Research Meeting, Washington, D. C. (Pediat. Res.. 8: 83 (1974))

44. This research was supported in part by Grant 14531 from the National Institutes of Health.

45. Dr. P. G. Holtzapple is recipient of Research Career Development Award No. 1-K4-HD-70026 from the National Institutes of Health.

46. Requests for reprints should be addressed to: P. G. Holtzapple, M.D. The Children's Hospital of Philadelphia, One Chidren's Center, 34th \& Civic Center Blvd., Philadelphia, Pa. 19104 (USA).

47. Accepted for publication June 25, 1975.

\title{
Bilirubin Interaction with Ganglioside: Possible Mechanism in Kernicterus
}

\author{
MARVIN L. WEIL'25) AND JOHN H. MENKES \\ Department of Pediatrics and Neurology. Harbor General Hospital Campus, UCLA School of Medicine and \\ Brentwood Veterans Administration Hospital, UCLA School of Medicine, Los Angeles, California, USA
}

\section{Extract}

Reaction of bilirubin with increasing amounts of ganglioside purified from neonatal brain significantly alters the spectral absorption of bilirubin in proportion to the quantity of ganglioside added. Increments in absorbance occur at $353 \mathrm{~nm}$ with a prompt but transient increase at $486 \mathrm{~nm}$. A decrease in absorbance occurs which is most marked at $447 \mathrm{~nm}$. When gangliosides are added to bilirubin $(9.1 \mu \mathrm{g} / \mathrm{ml}$ or $0.016 \mu \mathrm{M} / \mathrm{ml})$, the decrease in absorbance is essentially linear up to the highest concentration of purified ganglioside tested $(182 \mu \mathrm{g} / \mathrm{ml}$ or $0.097 \mu \mathrm{M} / \mathrm{ml})$, which represents a molar ratio of 6.1:1. The asymptotic nature of the bilirubin-ganglioside reaction as measured by the decrease in absorbance with time suggests a stoichiometric relationship between the two substances. An isosbestic point was demonstrated at $405 \mathrm{~nm}$. Observations reported here suggest bilirubin reaction with ganglioside is at least a two-step process.

\section{Speculation}

Bilirubin cytotoxicity may be related in part to plasma membrane effects which involve bilirubin interaction with ganglioside at concentrations which do not disturb mitochondrial metabolism. The difference between the ganglioside composition of infant and adult gray matter may in part explain the marked cytotoxicity of unconjugated bilirubin for the infant nervous system.

Kernicterus, a bilirubin encephalopathy, results from the accumulation of nonconjugated, non-albumin bound bilirubin which leads to well described changes in the nervous system (6). In most experiments. anoxia (1,9,18), or hypoglycemia (17), in association with hyperbilirubinemia, produces more profound lesions in the experimental model $(1,9,18)$ than nonanoxic hyperbilirubinemia. Neurons in such lesions demonstrate cytoplasm with myelin figures and dense bodies thought to be a pigment-lipid complex (10). Cytoplasmic membranous bodies have been described in enlarged Purkinje cell mitochondria of Gunn rats although none were present in astrocytes or oligodendrogliocytes (19). The enhanced susceptibility of specific regions of the nervous system to bilirubin toxicity as well as the increased susceptibility of the infantile nervous tissue has not been explained adequately.

Metabolic studies suggest that bilirubin pigment exerts four effects in mitochondrial reactions: (1) stimulation or inhibition of respiration depending on concentration of bilirubin. (2) abolition of respiratory control, (3) uncoupling of oxidative phosphorylation, and (4) induction of energy-requiring swelling. Levels of total bilirubin in the range of $10-40 \mu \mathrm{mol} /$ liter increase oxygen consumption of mitochondria $(2,11)$. Concentrations necessary to initiate uncoupling of oxidative phosphorylation within adult or infant rat liver and brain mitochondria in vitro are much higher than those found in the brains of adult Gunn rats with experimental bilirubin encephalopathy $(3,5)$. Furthermore, brain mitochondria of newborn guinea pigs with the clinical features of severe bilirubin encephalopathy fail to demonstrate uncoupling of oxidative phosphorylation (4). Bilirubin inhibition of oxygen uptake is greater for whole brain homogenate from newborn rats than from adult rats (21). Mitochondria from whole brain or cerebellum of newborn guinea pigs with bilirubin encephalopathy fail to exhibit 


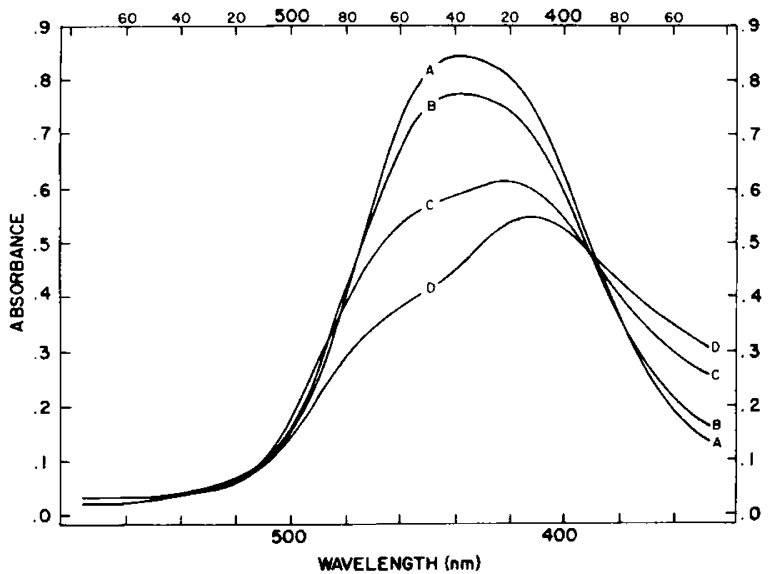

Fig. 1. Absorbance spectrum for bilirubin and various concentrations of ganglioside in aqueous $0.2 \mathrm{M}$ borate buffer with $1.0 \mathrm{mg} / \mathrm{ml}$ ascorbic acid. Reaction time was $60 \mathrm{~min}$. Bilirubin was $10 \mu \mathrm{g} / \mathrm{ml}(0.017 \mu \mathrm{M} / \mathrm{ml})$ in all solutions. Ganglioside concentrations were $A:$ none; $B: 31 \mu \mathrm{g} / \mathrm{ml}$ $(0.016 \mu \mathrm{M} / \mathrm{ml}) ; C: 150 \mu \mathrm{g} / \mathrm{ml}(0.080 \mu \mathrm{M} / \mathrm{ml}) ; D: 200 \mu \mathrm{g} / \mathrm{ml}(0.106$ $\mu \mathrm{M} / \mathrm{ml})$.

uncoupling of phosphorylation, and only a small portion of the total pigment in the brain is associated with mitochondria (4).

The ability of bilirubin to bind to protein molecules is clearly established; binding of bilirubin to albumin can be followed by alterations in spectral absorption $(14,15)$. Bilirubin binds reversibly to lipid: mitochondrial lipid produces two red shifts of absorption from $440 \mathrm{~nm}$ to $450 \mathrm{~nm}$ and $490 \mathrm{~nm}$ (12). This shift can be modified by addition of bovine serum albumin. Kahan et al. (8) have reported that bilirubin binds specifically with cerebral gangliosides derived from rat brain. These authors demonstrated chromatographic separation of a complex from brain and spinal cord in cases of kernicterus which demonstrated reactions of both ganglioside and bilirubin. Similar complexes were prepared in vitro using rat brain and aqueous bilirubin. This report presents evidence for a two-part interaction between bilirubin and purified ganglioside.

\section{METHODS AND MATERIALS}

Ganglioside, purified by the method of $\mathrm{O}^{\prime}$ Brien (13), was obtained from cortical gray matter of two infants; one died within the first 2 weeks of life and the other, a 2,070-g premature infant, died on the third day of life. Purity was ascertained by thin layer chromatography. The predominant gangliosides in the mixture used for the experiments were $G_{D l a}\left(G_{3}\right)$ and $G_{D I b}\left(G_{2}\right)$, an observation which is in agreement with the work of Suzuki (20). Based on the assumption that the sole fatty acid present in the ceramide moeity is stearate (18:0), the molecular weight of the ganglioside was 1,885. Bilirubin from Eastman Chemical Co., purified by the method of Henry (7), was dissolved in $0.2 \%$ $\mathrm{Na}_{2} \mathrm{CO}_{3}$. To minimize degradation, the $\mathrm{pH}$ of the solution was adjusted to $\mathrm{pH} 9.0$ with $0.2 \mathrm{M}$ borate buffer containing $1 \mathrm{mg} / \mathrm{ml}$ ascorbic acid. Ganglioside was dissolved in $0.2 \mathrm{M}$ borate buffer so that the final reaction mixture was $\mathrm{pH} 9.0 \pm 0.1$. All reactions were conducted in very subdued light or total darkness to avoid photodegradation. Spectrophotometric measurements were conducted with a Bausch \& Lomb recording spectrophotometer model 505.

Bilirubin solutions were quite unstable at acid or alkaline $\mathrm{pH}$ Sedimentation was noted below $\mathrm{pH} 8.6$ whereas enhanced lability occurred above $\mathrm{pH}$ 9.70. For this reason, $\mathrm{pH} 9.0$ was selected for all studies. Photodegradation of bilirubin at this $\mathrm{pH}$ was minimal. Ganglioside absorbance was undetectable for the concentrations and spectral range employed.

\section{RESULTS}

Bilirubin in $0.2 \mathrm{M}$ borate buffer $\mathrm{pH} 9.0$ has an absorption maximum at $438 \mathrm{~nm}$. Reaction of bilirubin with increasing amounts of ganglioside purified from neonatal brain significantly altered the spectral absorption of bilirubin in proportion to the quantity of ganglioside added (Fig. 1).

Experiments were done under conditions which excluded nearly all light, but photodegradation was still possible because of the light source of the spectrophotometer. Difference spectroscopy, which compensates in part for photodegradation during spectrophotometry, clearly demonstrated alteration in absorption spectrum when the reaction mixture was compared with control bilirubin solution. Progressive change in absorbance occurred with time when a mixture containing $7.2 \mu \mathrm{g} / \mathrm{ml}(0.012 \mu \mathrm{M} / \mathrm{ml})$ bilirubin and $162 \mu \mathrm{g} / \mathrm{ml}(0.086 \mu \mathrm{M} / \mathrm{ml})$ ganglioside was compared with 7.2 $\mu \mathrm{g} / \mathrm{ml}(0.012 \mu \mathrm{M} / \mathrm{ml})$ bilirubin (Fig. 2, top). Increments in absorbance occurred at $353 \mathrm{~nm}$ with a prompt but transient increase at $486 \mathrm{~nm}$. A decrease in absorbance occurs which is most marked at $447 \mathrm{~nm}$. When gangliosides are added to bilirubin $(9.1 \mu \mathrm{g} / \mathrm{ml}$ or $0.016 \mu \mathrm{M} / \mathrm{ml}$ ), the decrease in absorbance is essentially linear up to the highest concentration of purified ganglioside tested (182 $\mu \mathrm{g} / \mathrm{ml}$ or $0.097 \mu \mathrm{M} / \mathrm{ml}$ ), which represents a molar ratio of $6.1: 1$. The asymptotic nature of the bilirubin-ganglioside reaction, as measured by the decrease in absorbance with time (Fig. 2, bottom), suggested a stoichiometric relationship between the two substances. An isosbestic point was demonstrated at $405 \mathrm{~nm}$ for ganglioside isolated from both brains (Fig. 2,top). The insolubility of bilirubin in solutions of $\mathrm{pH} 8.3$ or below precluded experiments at the more acid $\mathrm{pH}$.

\section{DISCUSSION}

The development of a transient increase in absorbance at $486 \mathrm{~nm}$ corresponds to the wave length of a red shift to $490 \mathrm{~nm}$ described by Mustafa et al. (12) for the binding of bilirubin with mitochondrial lipids. However, the transient nature of this shift in our

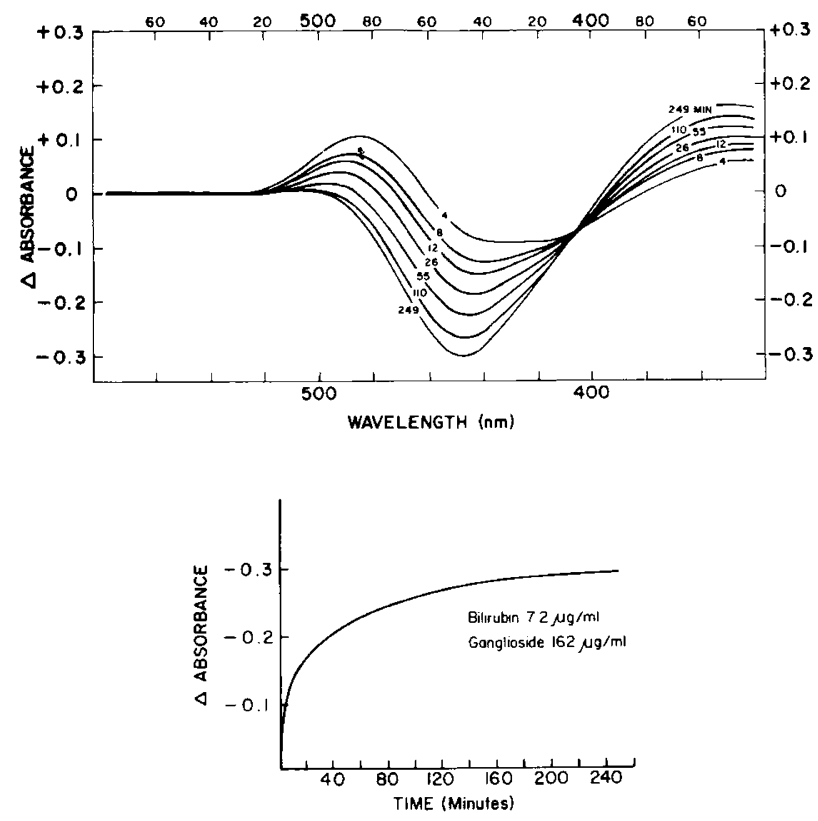

Fig. 2. Top: change in absorbance as demonstrated by difference spectroscopy for bilirubı $(7.2 \mu \mathrm{g} / \mathrm{ml}$ or $0.012 \mathrm{M} / \mathrm{ml})$ versus bilirubin $(7.2$ $\mu \mathrm{g} / \mathrm{ml}$ or $0.012 \mu \mathrm{M} / \mathrm{ml}$ ) plus ganglioside $(162 \mu \mathrm{g} / \mathrm{ml}$ or $0.086 \mu \mathrm{M} / \mathrm{ml})$. Serial recordings at reaction time as indicated (minutes). Bottom: decrease of absorbance at $447 \mathrm{~nm}$ as a function of time for reaction shown, top. 
studies, the marked decrease in absorbance at $437 \mathrm{~nm}$ which gradually and progressively shifts to $450 \mathrm{~nm}$, and the development of a second absorption peak at $353 \mathrm{~nm}$ differ from the reported observations for mitochondrial lipids. Transient increase in absorbance at $486 \mathrm{~nm}$ develops promptly and then disappears with time. This observation suggests that bilirubin is bound to gangliosides in two steps. At this point, we are unable to state what the essence of these two steps is, or, in fact, whether they involve bilirubin and gangliosides as such or their degradation products.

Ganglioside occurs in fetal brain even before myelin is present, probably in plasma membranes or other structures. Relatively low levels of ganglioside are found in purified preparations of brain mitochondria, myelin, nuclei, endoplasmic reticulum, and nerve ending particles. Ganglioside composition of whole rat brain changes with age: a relative shift occurring from trisialo- to monosialogangliosides. This shift is much more pronounced in highly purified myelin fractions (21). This difference may be a possible reason for the differential toxicity of bilirubin for newborn brain $(6)$ and brain homogenates $(3,5)$ in comparison with adult brain preparations. It has been suggested that membranous cytoplasmic bodies, rich in ganglioside, may be masses of plasma membrane (16). In bilirubin encephalopathy, these membranous cytoplasmic bodies may be bilirubin pigment-lipid complexes.

The observations reported here suggest that the bilirubin reaction with ganglioside is at least a two-step process. This reaction, with possible deleterious effect on selected cell plasma membranes, may be one mechanism for bilirubin toxicity. Our studies point to the possibility that gangliosides may alter plasma membranes producing cytotoxicity at tissue concentrations of bilirubin which are too low to uncouple mitochondrial oxidative phosphorylation. In particular, membrane alterations in the dendritic and synaptic regions of neurons may be important in producing cellular dysfunction.

\section{SUMMARY}

Spectral absorption is significantly altered when aqueous bilirubin is mixed with purified ganglioside. Difference spectrophotometry discloses a decrease in absorbance at $447 \mathrm{~nm}$ with an increase at $353 \mathrm{~nm}$ and a prompt but transient increase at $486 \mathrm{~nm}$. An isosbestic point occurs at $405 \mathrm{~nm}$. Interaction, perhaps molecular, between bilirubin and purified ganglioside is demonstrated by these changes for an in vitro system. Bilirubin may be toxic in vivo to cell elements rich in ganglioside by interference with plasma membrane function. Plasma membrane effects may be crucial at bilirubin concentrations which do not disturb mitochondrial metabolism.

\section{REFERENCES AND NOTES}

I. Chen, H.-C., Lin, C.-S., and Lein, I.-N.: Ultrastructural studies in experimental kernicterus. Amer. J. Path., 48: 683 (1966).

2. Cowger, M. L., Igo, R. P., and Labbe, R. F.: The mechanism of bilirubin toxicity studied with purified respiratory enzyme and tissue culture systems. Biochemistry 4: 2763 (1965).

3. Diamond, I.. and Schmid, R.: Experimental bilirubin encephalopathy. The mode of entry of bilirubin- ${ }^{14} \mathrm{C}$ into the central nervous system. J. Clin. Invest., 45: 678 (1966).

4. Diamond, 1., and Schmid, R.: Oxidative phosphorylation in experimental bilirubin encephalopathy. Science, 155: 1288 (1967)

5. Ernster L.: In: A. Sass-Kortsack: Kernicterus, p. 174 (University of Toronto Press, Toronto, 1961).

6. Haymaker, W., Margoles, C., Pentschaw, A., Jacob, H., Lindenberg, R., Arroyo, L. S., Stochdorph, O., and Stowens, D.: In: C. C. Swinyard: Kernicterus and Its Importance in Cerebral Palsy (Charles $C$ Thomas, Springfield. III., 1961)

7. Henry, R. V.: Clinical Chemistry: Principles and Techniques, p. 586 (Harper and Row, New York, 1967)

8. Kahan, L. L.. Timar, M., and Foldi, M.: Bilirubin-binding cerebral lipid. Acta Paediat Acad Sci. Hung, 9: 121, 1968.

9. Lucey, J. F Hibbard, E., Behrman, R. E., Esquivel de Gallardo, F. O., and Windle, $W$. F.: Kernicterus in asphyxiated newborn rhesus monkeys. Exp. Neurol. 9: 43 (1964).

10. Luse, S. A.: The neuron. In: J. Minkler: Pathology of the Nervous System, Vol. 1. p. 572 (McGraw-Hill Book Co., New York, 1968).

11. Mustafa, M. G., Cowger, M. L., and King, T. E.: Effects of bilirubin on mitochondrial reactions. J. Biol. Chem., 244: 6403 (1969).

12. Mustafa, M. G., and King. T. E.: Binding of bilirubin with lipid. J. Biol. Chem. 245: 1084 (1970).

13. O'Brien. J., and Sampson, E. L.: Lipid composition of the normal human brain: Gray matter, white matter, and myelin. J. Lipid Res., 6: 537 (1965).

14. Odell, G. B.: Studies in kernicterus. I. The protein binding of bilirubin. J. Clin. Invest., 38: 823 (1959).

15. Odell G. B. The dissociation of bilirubin from albumin and its clinical implications. J. Pediat., 55: 268 (1959).

16. Rouser. G., Nelson, G. J., Fleischer, S., and Simon, G.: In: D. Chapman

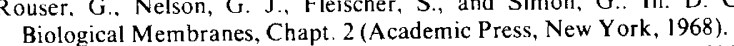

17. Rozdilsky, B., and Olszewski, J.: Experimental study of the toxicity of bilirubin in newborn animals. J. Neuropathol. Exp. Neurol. 20: 193 (1961).

18. Rozdilsky, B.: Kittens as experimental model for study of kernicterus. Amer. J. Dis. Child.. 111: 161 (1966).

19. Schutta, H. S., Johnson, L., and Neville, H. E.: Mitochondrial abnormalities in bilirubin encephalopathy. J. Neuropathol. Exp. Neurol. 29: 296 (1970).

20. Suzuki, K.: Ganglioside pattern of normal and pathological brains. In: S. M. Aronson and B. W. Volk: Inborn Disorders of Sphingolipid Metabolism (Pergamon Press, New York. 1967).

21. Suzuki, K., Poduslo. S. E., and Norton, W. T.: Gangliosides in the myelin fraction of developing rats. Biochim. Biophys. Acta, 144: 315 (1967).

22. Waters, W.: In: A. Sass-Kortsack: Kernicterus, p. 170 (University of Toronto Press, 1961).

23. Dr. M. L. Weil was supported in part by National Institute of Neurological Diseases and Blindness Fellowship F1! NB33-66.

24. Dr. J. H. Menkes was supported in part by National Institute of Neurological Diseases and Blindness/Research Grant NS-12256.

25. Requests for reprints should be addressed to: M. L. Weil, M. D.. Department of Pediatrics, Harbor General Hospital, 1000 W. Carson St., Torrance, Calif. 90509 (USA).

26. Accepted for publication June 25. 1975. 